\title{
Measuring Agency, Voice, and Gender Attitudes among Adolescents in South Asia
}

\author{
Amita N Vyas', Nitasha C Nagaraj', $\underline{\text { Woyni Teklay }}^{3}$, Richa Hingorani ${ }^{4}$, ]aya Luintel ${ }^{5}$, \\ Megan Landry ${ }^{6}$
}

\author{
${ }^{1}$ Associate Professor, ${ }^{2}$ Assistant Professor, ${ }^{6}$ Adjunct Faculty, Department of Prevention and Community Health, The George \\ Washington University, Milken Institute School of Public Health, Washington, DC, America. \\ ${ }^{3}$ Graduate Student Assistant, Department of Global Health, The George Washington University, Milken Institute School of \\ Public Health, Washington, DC, America. \\ ${ }^{4}$ India Program Lead, Girl Rising, New Delhi, India. \\ ${ }^{5}$ President \& Chief Executive Officer, The Story Kitchen, Kupondole, Lalitpur, Kathmandu, Nepal. \\ DOI: https://doi.org/10.24321/2349.2880.202113
}

\section{I $\quad \mathbf{N} \quad \mathbf{F} \quad \mathbf{O}$}

\section{Corresponding Author:}

Nitasha C Nagaraj, Department of Prevention and Community Health, The George Washington University, Milken Institute School of Public Health, Washington, DC, America.

E-mail Id:

nitasha@gwu.edu

Orcid Id:

https://orcid.org/0000-0002-6417-6692

How to cite this article:

Vyas AN, Nagaraj NC, Teklay W, Hingorani R, Luintel J, Landry M. Measuring Agency, Voice, and Gender Attitudes among Adolescents in South Asia. Ind J Youth Adol Health. 2021;8(4):8-21.

Date of Submission: 2021-09-27

Date of Acceptance: 2021-12-04

\section{$\begin{array}{llllllll}\mathbf{A} & \mathbf{B} & \mathbf{S} & \mathbf{T} & \mathbf{R} & \mathbf{A} & \mathbf{C} & \mathbf{T}\end{array}$}

Introduction: Voice, agency, and gender attitudes are concepts that are inextricably linked to empowerment, health, and long-term economic well-being for girls, women, families, and communities. The present study is aimed at developing and validating scales for voice, agency, and gender attitudes for adolescents in South Asia.

Method: Qualitative and quantitative research was conducted to develop and validate scales for voice, agency, and gender attitudes among adolescent boys and girls in urban, semi-urban, and rural settings in South Asia. There were two rounds of data collection with the first including 460 adolescents and the second round approximately 2 weeks later with 484 adolescents. The formative qualitative phase also included four focus groups with 30 girls and 25 boys between the ages of 10 and 16 years in Delhi and Lucknow, India.

Results: Thematic analysis led to the development of survey scale items in both English and Hindi and face validity testing was conducted with 10 adolescents aged 10-14 years in India. The data for validation of the scales were derived from self-reported surveys from adolescents 10-15 years old in public schools located in Delhi, India (urban), Uttar Pradesh, India (rural), and Gandaki Province, Nepal, (semi-urban). Six factors emerged from the analysis, and all six factors maintained dimensions of empowerment and are closely intertwined to voice, agency, and gender attitudes.

Conclusions: The measures that emerged from the analysis provide the foundation to expand upon different dimensions of voice, agency, and gender attitudes that are salient to adolescent boys and girls in South Asia.

Keywords: Voice, Agency, Gender Attittudes, Measurement, Adolescents, South Asia 


\section{Background}

There are 1.2 billion adolescents, aged 10-19 years of age in the world, making up $16 \%$ of the world's population. ${ }^{1}$ Ninety per cent of these adolescents live in low-to middle-income countries ${ }^{2}$ and it is during this adolescent period where physical and biological growth is arguably the largest growth period in one's life outside of the ages of 0-2 years. ${ }^{3}$ In addition to the physical and biological growth, adolescence is a time of puberty, sexual maturation, and at times, intimate mental and physical relationships, which presents an opportunity for growth, exploration, and self-identity. ${ }^{4}$ However, for many adolescents, particularly young girls, restrictions on freedom of movement, lack of voice and agency, and deeply entrenched gender norms exacerbate inequities they face, often forcing them into child marriage, early motherhood, increased household work, and genderbased violence. ${ }^{5,6}$ This is further compounded when the motivations and behaviours of young boys and men are not understood and therefore not included as a means to address societal barriers to gender equity. ${ }^{76,8,9}$ Across the globe, burgeoning programmes and interventions are aimed at increasing adolescents' voice, agency and genderequitable attitudes. However, current measures for these important outcomes have been created and validated with older adolescent girls and women, and mainly in highincome countries. It is imperative that developmentally salient measures are created and tested with adolescents in low- and middle-income countries, and for both adolescent girls and boys. These new measures will offer insights into whether and how voice, agency, and gender attitudes change across this significant developmental time period and will equip programme planners and evaluators with tangible ways to measure outcomes and impact.

\section{Voice and Agency}

Voice, the capacity to speak up and be heard, and agency, (sometimes referred to as empowerment), the capacity to make decisions about one's own life and act on them, have been shown to be instrumental in improving the health and well-being of not just women, but families, communities, and societies. ${ }^{10,11}$ Conversely, constraining a woman's agency and/ or voice can often subject her to violence, early marriage, loss of education and can deny her basic human rights which leads to further long-term gender inequities and poor health. ${ }^{129}$ Agency is usually measured in tandem with voice and both concepts are linked as critical constructs to achieving gender equality and empowerment. ${ }^{1310}$ Women are often at a systematic disadvantage in their ability to make effective choices and without participation in decision-making abilities, women lose their voice to speak up and challenge these norms, whether it is about decisions made in their homes, their ability to go to school, their spouse, reproduction, and/ or their choice to work. Removing these constraints and unleashing a woman's full productive potential allows for girls and women to exercise their voice and agency through efforts propelled via school, households, and/ or role models so that they can begin to question and transform the status quo, both at an individual and collective level. ${ }^{14}$

\section{Perceptions of Gender Norms and Gender Attitudes}

Gender norms are defined as characteristics that men and women possess which govern their behaviour in relation to culturally shared expectations. They are amongst the strongest social factors that influence an individual's attitudes, beliefs and behaviours. ${ }^{156,16}$ Like voice and agency, perceptions of gender norms become more solidified during adolescence as young girls and boys become more socially aware of what is expected of them as women and men. Further, they are solidified due to increasing societal pressures to conform to what is considered 'appropriate' for how men and women should behave. ${ }^{1712,18}$ Stereotypical gender norms characteristically encourage male dominance and supporting such stereotypes is associated with inequitable gender attitudes (e.g., an individual's perceptions, beliefs, or support of gender norms). Inequitable gender attitudes are often perpetuated through substance abuse, violence, household chores, and perpetration of violence. ${ }^{195,208,21,22}$

Contrarily, young girls and women that follow "culturally appropriate" gender norms end up curbing their opportunities, specifically in regard to voice and agency. It is hypothesised that increasing voice and agency and changing gender attitudes and norms among both adolescent girls and boys can improve the health and well-being of girls and women throughout the life course. ${ }^{238,2410,2512,2613,27}$ However, there is a gap in the research conducted amongst this young population and that too in developing nations.

\section{South Asia}

South Asia is one region of the world with deeply rooted discrimination and vast gender inequities. In India, young girls face constant gender discrimination, including deeply entrenched gender beliefs, lack of safety, and lack of equal access to secondary education leading to insufficient resource investment for girls, families, and community members. ${ }^{28,29}$ As illustrated on the gender inequality index, India ranks 131 out of 159 countries in terms of inequitable gender roles and responsibilities. This is a clear reflection of the gender-based discrimination that girls and women face throughout their life span and is demonstrated by the vast disparities in secondary education, employment, health, violence, and safety among women and girls compared to men and boys. ${ }^{306}$ The fourth Indian national family health survey revealed that nearly $40 \%$ of women in India have 
been physically mistreated by their husbands. ${ }^{31}$ Further, two out of three women who have ever experienced violence have never sought help but also have never shared with anyone else about the violence they experienced. In fact, of the women who have experienced sexual violence, $85 \%$ have never shared with anyone about those experiences, and only eight per cent have ever received some type of help. ${ }^{3217}$ Lack of education is also a considerable gendered difference in India as evidenced by the vast differences in literacy rates between males and females. In 2011, four out of every five males and two out of every three females, or $82 \%$ and $65 \%$, respectively, were considered literate in India. ${ }^{33}$

Similarly, in Nepal, girls and women face restricted access to education and employment, and extremely high rates of domestic violence. ${ }^{3418} \mathrm{~A}$ country that is characterised by persistent poverty and slow economic growth, ${ }^{35}$ education is often overlooked for women. The barriers to women participating in education are due to deeply rooted sociocultural realities, ${ }^{36}$ particularly in rural areas. ${ }^{3721}$ In a 2015 study conducted by Panthhe, boys were found to have at least 2 or more years of schooling than their female counterparts, and this gap was further widened in rural areas with boys having 3 or more years of schooling than girls. ${ }^{38}$ For many young girls in Nepal, oftentimes they were taken out of school to get married or help with housework. ${ }^{3923}$ Further, for many families, educating a girl is not perceived as worthy or valuable compared to investing in boys. ${ }^{4023}$ Finally, young girls who do have the privilege of obtaining some degree of education often lack female role models and safe environments to get to school. ${ }^{4123}$ It has been suggested by a national study that gender is the single greatest determinant of school participation among rural youth in Nepal. ${ }^{42}$

Gender discrimination is prevalent throughout the life course. However, adolescence is a critical time period during which this discrimination is catalysed, and simultaneously it is also when young people are developing their voice, agency, and gender attitudes. ${ }^{4312}$ Therefore, there has been increased investment in programmes and interventions to empower young people including building their voice and agency and developing gender-equitable attitudes. However, evaluating these programmes has been challenging given the paucity of valid and reliable measures for these constructs, especially for adolescent girls and boys living in low- and middle-income countries. The literature on measuring and defining these constructs has largely focused on women, with less attention on male engagement and the relationships between young men and women. Effectively engaging young adolescent boys during a time when they too are beginning to form ideals, voice and question societal norms, has shown to help change norms around violence, marriage, household gender norms and promote women's agency. ${ }^{449}$

It is clear from the research that voice and agency are instrumental in delaying early marriage, increasing participation by women in government, increasing the use of reproductive health services, and decreasing violence. ${ }^{459}$ We also know that changing gender attitudes and norms among adolescent girls and boys not only improves their overall health and well-being but can also be used as a measure of empowerment and gender equity. ${ }^{469}$ For these reasons, the purpose of this study is to construct, test, and validate these constructs for adolescent girls and boys in India and Nepal, and across urban, semi-urban, and rural settings.

\section{Methodology \\ Instrument Development}

The formative phase of this study led to the development of scales for voice, agency, and gender attitudes. First, an initial non-systematic literature review was completed to gather definitions and dimensions for voice, agency, and gender attitudes. An exhaustive list was developed and indepth discussions with partners in India and Nepal narrowed the dimensions for voice and agency to include access to and value of education, emotional efficacy, freedom of movement, decision-making in the family and community, aspirations, access to technology, opportunity for civic engagement and social action. For gender attitudes, the two primary dimensions that emerged were attributes and norms. Second, qualitative research was conducted to inform and develop survey items across these dimensions. A total of four focus groups with 30 girls and 25 boys between the ages of 10-16 years were conducted in Delhi and Lucknow, India. Separate focus groups were conducted for boys and girls. Each focus group was facilitated by a trained member of the research team and was conducted in Hindi. Focus group participants were recruited through our community partners in India and all the adolescents were enrolled in school. The community partners were nonprofit organisations with a history of working with our team, and who had the capacity and experience with qualitative research and focus groups. The adolescent participants were part of our community partners' existing programmes and interventions, and a convenience sample was recruited to ensure adequate saturation by age and gender. Participants were not directly asked about each of the dimensions but rather were asked a series of open-ended questions to assess their experiences and perceptions regarding: (1) education and their school environment; (2) challenges with family and friends; (3) relationships with family and peers; (4) future aspirations and challenges; (5) gendered experiences and perceptions of those experiences; (6) 
decision-making within schools and families; (7) restrictions and rules within families and schools; (8) access to mobile technology; and (9) experiences taking action in schools and communities. Participants shared their own personal experiences and stories, as well as their perceptions of what others their age experience. Focus group discussions were recorded and transcribed for analysis. Thematic analysis found that all the dimensions listed above for voice and agency except access to technology and civic engagement/ social action were relevant for these age groups. Finally, survey scale items were developed in both English and Hindi and face validity testing was conducted with 10 adolescents ( 5 girls and 5 boys) aged 10-14 years in India. Comprehension, clarity, and appropriateness of instructions and responses, and length of the survey were assessed, and feedback from the face validity testing was incorporated into the survey to refine language, terms, instructions, and data collection protocols.

The final instrument included 68-items and collected data on participants' sociodemographic characteristics such as grade, age, sex, and having female or male siblings. Thirtythree of the survey items specifically asked participants to respond to a series of questions by rating on a 4-point Likerttype scale whether they strongly disagree to strongly agree with the survey items. Survey items were newly developed or adapted from publicly available, validated instruments with related constructs around components of voice and agency, as well as gender norms and attributes, such as the Gender Equitable Measurement Scale created for the Gender Equity Movement in Schools programme in Mumbai, India, the UNICEF Evaluation of Empowering Young Girls and Women in Maharashtra, India, the Gender Equitable Men scale from the Compendium of Gender Scales, and the Girl Rising India Schools Campaign Evaluation. ${ }^{4714,48,49}$

Table 1 presents the three hypothesised domains - Voice and Agency, Gender Attributes, and Gender Norms - including the original 33 survey items, and the response options. Survey participants were asked to, "Please read each sentence and tick the box to show how much you agree or disagree with each of the statements".

Table I.Hypothesised Domains, Items, and Response Options

\begin{tabular}{|c|c|c|}
\hline Domains & Survey Items & Response Options \\
\hline \multirow{14}{*}{ Voice and agency } & $\begin{array}{l}\text { I feel comfortable starting a conversation with a girl I don't know very } \\
\text { well. }\end{array}$ & \multirow{14}{*}{$\begin{array}{c}\text { 4-point Likert-type } \\
\text { scale } \\
1 \text { - Strongly Disagree } \\
2 \text { - Disagree } \\
3 \text { - Agree } \\
\text { 4 - Strongly Agree }\end{array}$} \\
\hline & $\begin{array}{c}\text { I feel comfortable starting a conversation with a boy I don't know } \\
\text { very well. }\end{array}$ & \\
\hline & I feel comfortable expressing my opinions to my mother. & \\
\hline & I feel comfortable expressing my opinions to my father. & \\
\hline & I feel comfortable expressing my opinions to my teacher. & \\
\hline & I feel comfortable expressing my opinions to people that are my age. & \\
\hline & I feel comfortable expressing my opinions during class discussions. & \\
\hline & I can convince others of what I believe in. & \\
\hline & I can politely disagree with someone and share my point of view. & \\
\hline & I will decide when to get married. & \\
\hline & My parents will decide when I should get married. & \\
\hline & $\begin{array}{l}\text { Most of the time, I have little to say about what my parents decide } \\
\text { for me. }\end{array}$ & \\
\hline & I feel safe walking in the community during the day. & \\
\hline & I feel safe walking in the community during the night. & \\
\hline
\end{tabular}




\begin{tabular}{|c|c|c|}
\hline \multirow{5}{*}{ Gender attributes } & Boys are better at math and science than girls. & \multirow{5}{*}{$\begin{array}{l}\text { 4-point Likert-type } \\
\text { scale } \\
1 \text { - Strongly Disagree } \\
2 \text { - Disagree } \\
3 \text { - Agree } \\
4 \text { - Strongly Agree }\end{array}$} \\
\hline & Girls cannot do well in math or science. & \\
\hline & Boys are naturally better at sports than girls. & \\
\hline & $\begin{array}{c}\text { Giving the kids a bath and feeding the kids are a mother's } \\
\text { responsibility }\end{array}$ & \\
\hline & A wife should always obey her husband. & \\
\hline \multirow{14}{*}{ Gender norms } & Boys should get health services over girls. & \multirow{14}{*}{$\begin{array}{c}\text { 4-point Likert-type } \\
\text { scale } \\
1 \text { - Strongly Disagree } \\
2 \text { - Disagree } \\
3 \text { - Agree } \\
4 \text { - Strongly Agree }\end{array}$} \\
\hline & Boys should go to school over girls. & \\
\hline & Boys should be fed before girls during meals. & \\
\hline & Girls should choose on their own when to marry. & \\
\hline & Boys should choose on their own when to marry. & \\
\hline & Girls should be able to choose to work after marriage to earn money. & \\
\hline & Girls and boys should do the same amount of housework. & \\
\hline & Only men should work outside of the home. & \\
\hline & $\begin{array}{c}\begin{array}{c}\text { Since girls have to get married, they should not be sent for higher } \\
\text { education. }\end{array}\end{array}$ & \\
\hline & $\begin{array}{l}\text { There are times when a husband or boy needs to beat his girlfriend } \\
\text { or wife. }\end{array}$ & \\
\hline & $\begin{array}{l}\text { A woman should tolerate violence in order to keep her family } \\
\text { together. }\end{array}$ & \\
\hline & It is a girl's fault if a male student harasses her. & \\
\hline & It is a girl's fault if a male teacher harasses her. & \\
\hline & Girls provoke boys with short dresses. & \\
\hline
\end{tabular}

\section{Study Sample}

The data for this study were derived from self-reported surveys from adolescents aged 10-15 years in public schools located in Delhi, India (urban), Uttar Pradesh, India (rural), and Gandaki Province, Nepal (semi-urban).

There were two rounds of data collection with the first in January 2021 with 460 adolescents and the second round approximately 2 weeks later with 484 adolescents. Five survey participants reported ages that were outside of the sample and were dropped, resulting in a final analytic sample of 939 individuals - 458 in the first round and 481 in the second round. There was one observation from the second round of data collection with a missing response on a single survey item. That observation was dropped from the final Confirmatory Factor Analysis. Table 2 shows the survey sample distribution by age, grade, sex, region, siblings, and survey time (round 1 or round 2). There were no statistically significant differences in study sample characteristics between the two survey rounds.

Table 2.Study Participants' Characteristics by Survey Time Period

\begin{tabular}{|c|c|c|c|}
\hline Variables & $\begin{array}{c}\text { Total } \\
939(100 \%) \\
\text { n (\%) }\end{array}$ & $\begin{array}{c}\text { First Round } \\
458(48.8 \%) \\
n(\%)\end{array}$ & $\begin{array}{c}\text { Second Round } \\
481(51.2 \%) \\
n(\%)\end{array}$ \\
\hline \multicolumn{4}{|c|}{ Age (years) } \\
\hline 10 & $92(9.8)$ & $45(9.8)$ & $47(9.8)$ \\
\hline 11 & $128(13.6)$ & 67 (14.6) & 61 (12.7) \\
\hline 12 & $235(25.0)$ & $111(24.2)$ & $124(25.8)$ \\
\hline
\end{tabular}




\begin{tabular}{|c|c|c|c|}
\hline 13 & 268 (28.5) & $125(27.2)$ & $143(29.5)$ \\
\hline 14 & $205(21.8)$ & $106(23.1)$ & $99(20.6)$ \\
\hline 15 & $11(1.2)$ & $4(0.9)$ & $7(1.5)$ \\
\hline \multicolumn{4}{|c|}{ Grade } \\
\hline 5th & $184(19.6)$ & $92(20.1)$ & $92(19.1)$ \\
\hline 6th & $279(29.6)$ & $148(32.3)$ & $131(27.2)$ \\
\hline 7th & $257(27.2)$ & $117(25.6)$ & $138(28.7)$ \\
\hline 8th & $221(23.5)$ & $101(22.1)$ & $120(25.0)$ \\
\hline \multicolumn{4}{|c|}{ Location } \\
\hline Delhi, India & $258(27.5)$ & $118(25.8)$ & $140(29.1)$ \\
\hline Uttar Pradesh, India & $277(29.5 \%)$ & $139(30.4)$ & $138(28.7)$ \\
\hline Gandaki Province, Nepal & $404(43.0)$ & 201 (43.9) & $203(42.2)$ \\
\hline \multicolumn{4}{|c|}{ Siblings } \\
\hline Has brothers & 675 (71.9\%) & $328(71.6)$ & $347(72.1)$ \\
\hline Has sisters & $625(66.6)$ & $299(65.3)$ & $326(67.8)$ \\
\hline \multicolumn{4}{|c|}{ Gender } \\
\hline Male & $408(43.5)$ & 201 (43.9) & $207(43.0)$ \\
\hline Female & $531(56.6)$ & $257(56.1)$ & $274(57.0)$ \\
\hline
\end{tabular}

\section{Data Collection}

The in-country research staff underwent data collection training and followed a standardised protocol in delivering the survey to participants, which was completed via paper and pencil in an afterschool setting with no teachers or other authority figures involved. The survey was developed in English then translated to Hindi/ Nepali and back-translated to English by two native Hindi and Nepalese speakers so that proper dialect and language nuances were addressed. Prior to the start of each phase of data collection, the community partners reached out to the parents of the participants to provide an overview of the project and data collection instruments and provide a copy of the consent. Verbal consent was obtained from the parents for their child to participate by the in-country community partners. Upon survey completion, the in-country research team entered the completed surveys into a pre-populated survey database in Microsoft Excel. The final datasets were securely transferred to the US research team to download, clean, and analyse.

\section{Analysis}

Univariate analyses were conducted to examine frequencies and distributions of the study variables of interest. The first round of data $(n=458)$ served as the testing sample while the second round served as the validation sample ( $n$
$=480$ ). Exploratory factor analysis (EFA) was conducted on the first round of data to determine the factor structure and examine if the three hypothesised factors emerged. EFA was run with no predetermined factor structure and no restrictions in order to explore the factor structure. Factors with eigenvalues greater than one (1) were retained. The principal axis factor method, with an oblique rotation, was used because we anticipated moderate correlations between factors. All items were expected to load onto a single factor and items with factor loadings less than 0.40 were removed.

Confirmatory factor analysis (CFA) was conducted on the second round of data as the validation sample to confirm model fit. The degree of model fit was assessed with chisquare goodness of fit statistic $\left(X^{2}\right)$, root-mean-square error of approximation (RMSEA), standardised root mean square residual (SRMR), comparative fit index (CFI), and the Tucker Lewis index (TLI). ${ }^{50,51}$ Modification indices were explored to improve model fit and validate the factor structure from the initial EFA results. Internal reliability was measured for each of the final factors using Cronbach's alpha, in which an alpha $>0.70$ was considered reliable. All analyses were conducted in Stata SE 15.1, StataCorp LLC, TX. As the research partner, the George Washington University (GW) Internal Review Board reviewed and approved this study (IRB \#191568), and all of the partners in India were listed as 
part of the GW research team and underwent CITI training on human subjects research and ethics. The raw data were not transferred to the international funding agency and remains with the lead organisation in India. GW developed the instruments and conducted the analysis.

\section{Results}

The EFA results surprisingly revealed 8 factors with Eigenvalues $>1$. One factor was eliminated from the final EFA structure due to only one item, Girls and boys should do the same amount of housework, loading on that factor. Additionally, six of the 33 items had factor loadings below 0.4 on any factor so those items were also eliminated:

Giving the kids a bath and feeding the kids are a mother's responsibility

A woman should tolerate violence in order to keep her family together

I can politely disagree with someone and share my point of view

I feel safe walking in the community during the day Girls provoke boys with short dresses

I feel safe walking in the community during the night

The remaining 26 items unexpectedly loaded onto 7 factors. None of the items loaded onto another factor with a loading greater than 0.37 , which suggests that they are measuring distinct constructs. Three of the 7 factors only had two items load onto those factors, suggesting that we have not fully measured those unexpected constructs with the survey items.
Table 3 presents the EFA results and lists the individual items within each factor and the corresponding factor loadings. The 7 factors resulting from the EFA are identified as gender attributes, voice, gender norms, agency, genderbased violence (GBV) norms, self-efficacy, and locus of control. All the factors are aligned with the dimensions identified in the formative phase except for the locus of control. However, it is conceptually defined as how strongly people believe they have control over the situations and experiences that affect their lives and therefore, it is one dimension of agency. ${ }^{52}$

Following the EFA, CFA was conducted using the second round of data as the validation sample to confirm the factor structure resulting from the EFA testing sample. We specified an over-identified model with 351 data points and 58 parameters to be estimated. For the CFA, each item from the final EFA model was expected to load onto a single factor and reliability for each factor, as measured by Cronbach's alpha, was expected to be above 0.70 .

The two items from Factor 7 (Locus of Control) in the EFA model, Most of the time, I have little to say about what my parents decide for me, and There are times when a husband or boy needs to beat his girlfriend or wife had factor loadings of $0.066(p=0.437)$ and $-0.295(p=0.363)$, respectively. Thus, Factor 7 and the two corresponding items were eliminated from the final CFA model, resulting in 6 factors - gender attributes, voice, gender norms, agency, GBV norms, and self-efficacy.

Table 3.Factor Loadings from EFA Results

\begin{tabular}{|c|c|}
\hline Factor 1 (Gender Attributes) & EFA Factor Loadings \\
\hline Boys are better at math and science than girls. & 0.876 \\
\hline Since girls have to get married, they should not be sent for higher education. & 0.785 \\
\hline Girls cannot do well in math or science. & 0.701 \\
\hline Boys are naturally better at sports than girls. & 0.670 \\
\hline Only men should work outside of the home. & 0.652 \\
\hline A wife should always obey her husband. & 0.494 \\
\hline \multicolumn{2}{|c|}{ Factor 2 (Voice) } \\
\hline I feel comfortable expressing my opinions to my mother. \\
\hline I feel comfortable expressing my opinions to my father. \\
\hline I can convince others of what I believe in. & 0.826 \\
\hline I feel comfortable expressing my opinions to my teacher. & 0.738 \\
\hline I feel comfortable expressing my opinions to people that are my age. & 0.700 \\
\hline I feel comfortable expressing my opinions during class discussions. & 0.658 \\
\hline My parents will decide when I should get married. & 0.585 \\
\hline
\end{tabular}




\begin{tabular}{|c|c|}
\hline \multicolumn{2}{|l|}{ Factor 3 (Gender Norms) } \\
\hline Boys should get health services over girls. & 0.843 \\
\hline Boys should go to school over girls. & 0.748 \\
\hline Boys should be fed before girls during meals. & 0.748 \\
\hline \multicolumn{2}{|l|}{ Factor 4 (Agency) } \\
\hline Girls should choose on their own when to marry. & 0.811 \\
\hline I will decide when to get married. & 0.727 \\
\hline Boys should choose on their own when to marry. & 0.694 \\
\hline Girls should be able to choose to work after marriage to earn money. & 0.415 \\
\hline \multicolumn{2}{|l|}{ Factor 5 (GBV Norms) } \\
\hline It is a girl's fault if a male student harasses her. & 0.875 \\
\hline It is a girl's fault if a male teacher harasses her. & 0.605 \\
\hline \multicolumn{2}{|l|}{ Factor 6 (Self-Efficacy) } \\
\hline I feel comfortable starting a conversation with a girl I don't know very well. & 0.808 \\
\hline I feel comfortable starting a conversation with a boy I don't know very well. & 0.675 \\
\hline \multicolumn{2}{|l|}{ Factor 7 (Locus of Control) } \\
\hline Most of the time, I have little to say about what my parents decide for me. & 0.788 \\
\hline There are times when a husband or boy needs to beat his girlfriend or wife. & 0.536 \\
\hline
\end{tabular}

Modification indices were then estimated in order to improve model fit. Each Lagrange Multiplier was reviewed and it was decided whether there was a reasonable basis for including the correlated errors as a result of the large Lagrange Multiplier in the modification indices. We estimated five covariances with large Lagrange Multiplier modification indices between error terms within and across factors. Model fit statistics for the original model and the modified model are reported in Table 4, along with the acceptable threshold for each fit index. Error covariances were estimated one at a time and are indicated in Table 5.

\section{Table 4.Model Fit Statistics}

\begin{tabular}{|c|c|c|c|}
\hline Fitness Index & $\begin{array}{c}\text { Model 1 - } \\
\text { original }\end{array}$ & $\begin{array}{c}\text { Model 2 - } \\
\text { modified }\end{array}$ & $\begin{array}{c}\text { Acceptable } \\
\text { Threshold }\end{array}$ \\
\hline $\begin{array}{c}\text { Chi-square } \\
\text { goodness of fit } \\
\text { statistic, } X^{2} / \mathrm{df}\end{array}$ & $\begin{array}{c}559.39 / \\
278 \\
=2.01\end{array}$ & $\begin{array}{c}441.92 / \\
232 \\
=1.90\end{array}$ & $\leq 2$ \\
\hline $\begin{array}{c}\text { Root-mean- } \\
\text { square error of } \\
\text { approximation } \\
\text { (RMSEA) }\end{array}$ & 0.046 & 0.043 & $<0.05$ \\
\hline $\begin{array}{c}\text { Standardised } \\
\text { root mean } \\
\text { square residual } \\
\text { (SRMR) }\end{array}$ & 0.053 & 0.052 & $<0.09$ \\
\hline
\end{tabular}

\begin{tabular}{|c|c|c|c|}
\hline $\begin{array}{c}\text { Comparative } \\
\text { fit index (CFI) }\end{array}$ & 0.868 & 0.900 & $>0.90$ \\
\hline $\begin{array}{c}\text { Tucker Lewis } \\
\text { index (TLI) }\end{array}$ & 0.846 & 0.880 & $>0.90$ \\
\hline
\end{tabular}

Model two fit the data better than the saturated model. The chi-square statistic suggests a poor fit $(p<0.001)$, but chisquare/ degrees of freedom suggests that the model may be acceptable $(\leq 2)$ so we interpreted the remaining goodness of fit statistics. All indices are acceptable except for the Tucker Lewis Index, which is approaching an acceptable fit of $>0.90$. The 6-factor model with standardised estimates, standard errors, and composite reliability by factor is presented in Table 5. Three standardised estimates were $<0.400$ but all were statistically significant at $p<0.001$. Cronbach's alpha scores, which measure reliability, did not achieve the desirable 0.70 for all 6 factors, but good fit was superior to reliability for this analysis. ${ }^{53}$ The final results of this analysis included examining the Cronbach's alpha scores between the first and second rounds of the analysis. Table 6 presents Cronbach's alpha scores for each factor by gender and region. Overall, the alpha scores remained similar between the two survey time points, except for five instances when the first survey time point suggested higher, reliable alpha scores for Factor 2 (Voice) in Uttar Pradesh, Factor 3 (Gender Norms) for males, Delhi, and Uttar Pradesh, and Factor 4 (Agency) in Uttar Pradesh. 
Table 5.CFA results - 6-Factors with Standardised Estimates, Standard Errors, and Composite Reliability

\begin{tabular}{|c|c|c|}
\hline Factors and Associated Survey Items & $\begin{array}{l}\text { Standardised } \\
\text { Estimates } \\
\text { (Standard Error) }\end{array}$ & $\begin{array}{l}\text { Composite } \\
\text { Reliability }\end{array}$ \\
\hline Factor 1 (Gender Attributes) & alpha $=0.7594$ & \\
\hline Boys are better at math and science than girls. ${ }^{d}$ & $\begin{array}{l}0.716^{* * *} \\
(.031)\end{array}$ & 0.510 \\
\hline $\begin{array}{l}\text { Since girls have to get married, they should not be sent for higher } \\
\text { education. }\end{array}$ & $\begin{array}{l}0.651^{* * *} \\
(.033)\end{array}$ & 0.424 \\
\hline Girls cannot do well in math or science. & $\begin{array}{l}0.614^{* * *} \\
(.035)\end{array}$ & 0.378 \\
\hline Boys are naturally better at sports than girls. ${ }^{d}$ & $\begin{array}{l}0.582 * * * \\
(.038)\end{array}$ & 0.338 \\
\hline Only men should work outside of the home. & $\begin{array}{l}0.603 * * * \\
(.036)\end{array}$ & 0.363 \\
\hline A wife should always obey her husband. & $\begin{array}{c}0.365^{* * *} \\
(0.045)\end{array}$ & 0.132 \\
\hline Factor 2 (Voice) & alpha $=0.6826$ & \\
\hline I feel comfortable expressing my opinions to my mother. ${ }^{e}$ & $\begin{array}{c}0.659 * * * \\
(0.040)\end{array}$ & 0.440 \\
\hline I feel comfortable expressing my opinions to my father. ${ }^{b}$ & $\begin{array}{l}0.506 * * * \\
(0.508)\end{array}$ & 0.257 \\
\hline I can convince others of what I believe in. ${ }^{c}$ & $\begin{array}{l}0.427 * * * \\
(0.047)\end{array}$ & 0.183 \\
\hline I feel comfortable expressing my opinions to my teacher. ${ }^{b}$ & $\begin{array}{l}0.398 * * * \\
(0.049)\end{array}$ & 0.157 \\
\hline I feel comfortable expressing my opinions to people that are my age. & $\begin{array}{c}0.488 * * * \\
(0.045)\end{array}$ & 0.237 \\
\hline I feel comfortable expressing my opinions during class discussions. & $\begin{array}{l}0.525 * * * \\
(0.044)\end{array}$ & 0.276 \\
\hline My parents will decide when I should get married. & $\begin{array}{c}0.323 * * * \\
(0.050)\end{array}$ & 0.105 \\
\hline Factor 3 (Gender Norms) & alpha $=0.5841$ & \\
\hline Boys should get health services over girls. ${ }^{e}$ & $\begin{array}{c}0.586 * * * \\
(0.040)\end{array}$ & 0.343 \\
\hline Boys should go to school over girls. & $\begin{array}{c}0.574 * * * \\
(0.040)\end{array}$ & 0.326 \\
\hline Boys should be fed before girls during meals. & $\begin{array}{c}0.563^{* * *} \\
(0.040)\end{array}$ & 0.313 \\
\hline Factor 4 (Agency) & alpha $=0.6075$ & \\
\hline Girls should choose on their own when to marry. & $\begin{array}{c}0.539 * * * \\
(0.043)\end{array}$ & 0.297 \\
\hline
\end{tabular}




\begin{tabular}{|c|c|c|}
\hline I will decide when to get married. & $\begin{array}{c}0.447^{* * *} \\
(0.048)\end{array}$ & 0.198 \\
\hline Boys should choose on their own when to marry. ${ }^{\text {ac }}$ & $\begin{array}{l}0.742 * * * \\
(0.048)\end{array}$ & 0.547 \\
\hline Girls should be able to choose to work after marriage to earn money. ${ }^{a}$ & $\begin{array}{l}0.508^{* * *} \\
(0.058)\end{array}$ & 0.258 \\
\hline Factor 5 (GBV Norms) & alpha $=0.4527$ & \\
\hline It is a girl's fault if a male student harasses her. & $\begin{array}{c}0.549 * * * \\
(0.051)\end{array}$ & 0.302 \\
\hline It is a girl's fault if a male teacher harasses her. & $\begin{array}{c}0.531^{* * *} \\
(0.051)\end{array}$ & 0.282 \\
\hline Factor 6 (Self-Efficacy) & alpha $=0.4443$ & \\
\hline $\begin{array}{l}\text { I feel comfortable starting a conversation with a girl I don't know very } \\
\text { well. }\end{array}$ & $\begin{array}{l}0.533 * * * \\
(0.061)\end{array}$ & 0.288 \\
\hline $\begin{array}{l}\text { I feel comfortable starting a conversation with a boy I don't know very } \\
\text { well. }\end{array}$ & $\begin{array}{l}0.533 * * * \\
(0.061)\end{array}$ & 0.284 \\
\hline
\end{tabular}

$* * * p<0.001 ; a, b, c, d . e$ Correlated error terms

Table 6.Cronbach's Alpha Scores between First and Second Rounds by Gender and Region

\begin{tabular}{|c|c|c|c|}
\hline Factors & Gender and Region & $\begin{array}{l}\text { First-round } \\
\text { Alpha Score }\end{array}$ & $\begin{array}{l}\text { Second-round } \\
\text { Alpha Score }\end{array}$ \\
\hline \multicolumn{4}{|c|}{ Factor 1 (Gender attributes) } \\
\hline \multirow{2}{*}{ Gender } & Female & 0.8202 & 0.7826 \\
\hline & Male & 0.7394 & 0.7255 \\
\hline \multirow{3}{*}{ Region } & Delhi & 0.6707 & 0.7122 \\
\hline & UP & 0.8757 & 0.8294 \\
\hline & Nepal & 0.6560 & 0.6928 \\
\hline \multicolumn{4}{|c|}{ Factor 2 (Voice) } \\
\hline \multirow{2}{*}{ Gender } & Female & 0.7323 & 0.6626 \\
\hline & Male & 0.7527 & 0.6986 \\
\hline \multirow{3}{*}{ Region } & Delhi & 0.6226 & 0.6243 \\
\hline & UP & 0.8115 & 0.6129 \\
\hline & Nepal & 0.6113 & 0.6429 \\
\hline \multicolumn{4}{|c|}{ Factor 3 (Gender norms) } \\
\hline \multirow{2}{*}{ Gender } & Female & 0.6783 & 0.5916 \\
\hline & Male & 0.7581 & 0.5712 \\
\hline \multirow{3}{*}{ Region } & Delhi & 0.7514 & 0.4902 \\
\hline & UP & 0.7164 & 0.6241 \\
\hline & Nepal & 0.6343 & 0.5730 \\
\hline \multicolumn{4}{|c|}{ Factor 4 (Agency) } \\
\hline \multirow{2}{*}{ Gender } & Female & 0.7094 & 0.6648 \\
\hline & Male & 0.6181 & 0.5056 \\
\hline \multirow{2}{*}{ Region } & Delhi & 0.4900 & 0.4390 \\
\hline & UP & 0.7592 & 0.4457 \\
\hline
\end{tabular}




\begin{tabular}{|c|c|c|c|}
\hline \multicolumn{2}{|c|}{ Nepal } & 0.6790 & 0.7274 \\
\hline \multicolumn{3}{|c|}{ Factor 5 (GBV norms) } \\
\hline \multirow{3}{*}{ Gender } & Female & 0.4147 & 0.3466 \\
\cline { 2 - 4 } & Male & 0.5142 & 0.5034 \\
\hline \multirow{3}{*}{ Region } & Delhi & 0.2022 & 0.2819 \\
\cline { 2 - 4 } & UP & 0.5813 & 0.4576 \\
\cline { 2 - 4 } & Nepal & 0.5224 & 0.5423 \\
\hline \multirow{2}{*}{ Gender } & Factor 6 (Self-efficacy) & \\
\hline \multirow{2}{*}{ Region } & Female & 0.3352 & 0.4030 \\
\hline & Male & 0.5023 & 0.4950 \\
\hline & Delhi & 0.2826 & 0.2492 \\
\cline { 2 - 4 } & UP & 0.3454 & 0.4017 \\
\cline { 2 - 4 } & Nepal & 0.5906 & 0.5810 \\
\hline
\end{tabular}

\section{Discussion}

Voice, agency, and gender attitudes are becoming more important in public health research and to interventions focused on decreasing gender inequities and increasing adolescent empowerment. To expand our understanding of adolescents' voice, agency, and gender attitudes, and their trajectories over time, as well as if and how interventions can change these constructs, it is critical that culturally and developmentally appropriate measures exist, for both girls and boys. The aim of this study was to develop, adapt, and validate a set of measures to capture dimensions of voice, agency and gender attitudes that are salient to adolescents belonging to the age group of 10-15 years in a South Asian context. The measures presented in this article evolved from previous studies evaluating a gender sensitisation programme for adolescent girls and boys in India, ${ }^{5414}$ as well as formative research which led to the final structure confirmed by the EFA/ CFA results.

Although we originally anticipated three factors for voice, agency and gender attitudes capturing the dimensions we identified in the formative phase, six factors emerged from the analysis (Table 7). However, all six factors maintained dimensions of empowerment and are closely intertwined to voice, agency, and gender attitudes. In the EFA, 26 items unexpectedly loaded onto seven factors, and none of the items loaded onto another factor with a loading greater than 0.37 . This suggests that these items are indeed measuring distinct constructs. Further, three of the seven factors only had two items each suggesting that we had not fully measured those unexpected constructs with the survey items, and that these factors are important and warrant greater attention in future measurement development.

Given that six factors emerged from our research, it is likely that broad concepts of voice, agency, and gender attitudes are more nuanced, particularly for adolescent boys and girls in South Asia, for example, perceptions of gender attributes, gender norms and GBV norms loaded onto three separate factors reflecting that these are distinct from one another and should not be aggregated together under the domain of gender attitudes. It is plausible that adolescents' perceptions of gender attributes, gender norms and GBV norms vary from one another, and an adolescent with perceptions of equitable gender norms could in fact have inequitable or negative perceptions of GBV norms or vice versa. Further, interventions that focus broadly on gender attributes or norms may not be effective at changing GBV norms among adolescents, nor may GBV aimed programmes change broader gender norms or perceptions of gender attributes. Although these factors are interconnected, adolescents may not perceive these to be the same and may have different perceptions of these constructs.

Construction and development of voice, agency, and gender attitudes occur during adolescence which begins at 10 years of age. Adolescence is also one of the most critical periods of development as health and well-being at this age have lifelong consequences. There is currently limited understanding and rigorous measurement testing that has been focused on adolescents in a South Asian context as most measures have been developed for adults in highincome countries. Voice, agency, and gender attitudes change during the adolescent time period, and throughout adulthood. In fact, a person's context, life circumstance, and time period of the life course are key factors associated with these concepts, and therefore utilising measures that have been tested and validated with adults is not reliable when working with adolescents. The results presented here have operationalised a set of measures that can be used with younger adolescents (aged 10-15 years), allowing future research to measure changes in these constructs through the adolescent time period, and to evaluate interventions aimed at changing these constructs during early adolescence. 
Table 7.Final Factors and Definitions

\begin{tabular}{|c|c|}
\hline Factor & Definition \\
\hline Gender attributes & $\begin{array}{l}\text { A direct comparison between boys and girls in which boys are considered to be superior } \\
\text { to girls. }{ }^{14}\end{array}$ \\
\hline Voice & The capacity to speak up and be heard. ${ }^{10}$ \\
\hline Gender norms & $\begin{array}{l}\text { Culturally shared expectations about the characteristics that men and women should } \\
\text { possess and how they should behave. This includes socially acceptable rules about roles, } \\
\text { traits, behaviours, and power associated with masculinity and femininity in a culture. }{ }^{5714}\end{array}$ \\
\hline Agency & $\begin{array}{l}\text { Empowerment and the capacity to make decisions about one's own life and act on } \\
\text { them. } .^{5810}\end{array}$ \\
\hline GBV norms & $\begin{array}{l}\text { Experiences of social norms regarding physical and/ or sexual abuse of girls and } \\
\text { women. }\end{array}$ \\
\hline Self-efficacy & Perceptions on one's ability to organise, perform, and accomplish a given behaviour ${ }^{60,61}$ \\
\hline
\end{tabular}

Many health behaviours are acquired during early adolescence that are influenced by voice, agency, and gender attitudes, and these have implications for both girls and boys. Negative consequences for girls include child marriage, poor health, lack of education, depression, child pregnancy, and violence. ${ }^{625,636}$ The consequences for boys include engaging in physical violence more often than girls, being more prone to substance abuse and suicide, experiencing greater mortality as a result of unintentional injuries, and then later as adults, men experiencing shorter life expectancies than women. ${ }^{647}$ During this developmental time period, boys and girls engage with and construct their own voice, agency, and gender-based understanding around concepts of what it means to be a girl or a boy. Therefore, it is critical that the development of measures is conducted with both boys and girls, and to date, this has been limited. Further, programmes and interventions are beginning to engage boys in empowerment programmes with a heightened understanding that when boys and men are engaged in understanding the importance of gender equality and provided the tools to help shift dominant norms and ideas about gender and masculinity, they are more likely to become allies in challenging patriarchal beliefs, practices, institutions, and structures that drive inequality between men and women. The measures developed and tested in this article included both girls and boys and provide tangible mechanisms by which programmes that engage both sexes can measure outcomes. Finally, not much is known about voice, agency, and gender attitudes among young adolescents in low- and middle-income countries, such and India and Nepal, and even less is known about these constructs in rural areas. The factors that emerged provide new measures for both India and Nepal, and for urban, semi-urban, and rural settings.

There are limitations to this study. First, the formative phase did not include a rigorous systematic review of the literature nor did it include the development of a conceptual/ theoretical framework for voice, agency, and gender attitudes. Instead, the initial phase focused on qualitative research and thematic analysis to build upon previous studies on gender attitudes and gender sensitisation programmes. Second, as noted above, three of the seven factors only had two items each suggesting that we have not fully measured those constructs with the survey items we included, and that these factors are important constructs that warrant greater attention in future measurement development. Despite these limitations, the strengths of the study discussed above cannot be overstated as the findings fill a critical gap in the research surrounding voice, agency, and gender attitudes among adolescent girls and boys. Further, the results provide new insights into the dimensions of voice, agency, and gender attitudes to guide future research and measurement development. Most importantly, the surge of new programmes focused on gender sensitisation and empowerment can operationalise the measures presented in this manuscript to appropriately test outcomes and impact.

\section{Conclusion}

Around the world, there is greater interest and focus on adolescent girls' empowerment, and how voice, agency, and gender attitudes are critical factors that influence long-term change. Although voice, agency, and gender attitudes among adolescents have garnered more attention in recent years, the measures have been lagging. Many interventions on the ground are aimed at building agency and voice, yet these same programmes are not equipped with valid and developmentally appropriate measures to test programmatic impact. Measures for voice, agency, and gender attitudes will provide what is needed to document these important concepts of empowerment and will eventually allow for a change in the narrative for adolescent boys and girls. This study developed and validated a set of measures for voice, agency, and gender 
attitudes that can be utilised with younger adolescents aged 10-15 years in South Asia, and in urban, semi-urban, and rural settings. Further, the factors that emerged from the EFA/ CFA analysis provide the foundation to expand upon different dimensions of voice, agency, and gender attitudes that are salient to adolescent boys and girls in South Asia.

\section{Acknowledgement}

We would like to thank our local partners, Navsrishti in Delhi, Gramin Puranirman Sansthan in Lucknow, and The Story Kitchen in Nepal, for assistance with all the data collection efforts in each of these communities. It took numerous hours, emails, and zoom calls to finalise the research instruments, measures, and data collection schedule. Thank you for allowing us to be a part of your communities. Your commitment to young people and gender equality is an inspiration. We would like to thank Nidhi Dubey, Senior Vice President at Global Health Strategies for her leadership and dedication to this project.

We would also like to thank Dr Sean Cleary at The George Washington University Milken Institute School of Public Health. His expertise in measurement methodology was truly invaluable in advising the authors in both relaying the exploratory and confirmatory factor analyses.

\section{Funding Source}

Funding support was provided by Gender and Adolescence: Global Evidence (GAGE). GAGE was not involved in the conduct of the research or preparation of this article.

\section{Conflict of Interest: None \\ References}

1. United Nations Children's Fund. The state of the world's children 2011. Adolescence: an age of opportunity. New York: UNICEF; 2011. [Google Scholar]

2. World Health Organization. Adolescent health research priorities: report of a Technical Consultation 13th and 14th October 2015, Geneva, Switzerland. World Health Organization; 2015.

3. United Nations International Children's Emergency Fund (UNICEF) [Internet]. UNICEF programme guidance for the second decade: programming with and for adolescents; 2018 [cited 2021 Aug 29]. Available from: https://www.unicef.org/media/57336/file

4. United Nations International Children's Emergency Fund (UNICEF) [Internet]. Global initiative on out-ofschool children: South Asia regional study, covering Bangladesh, India, Pakistan and Sri Lanka; 2014 [cited 2021 Aug 29]. Available from: https://reliefweb.int/ report/bangladesh/global-initiative-out-schoolchildren-south-asia-regional-study-covering

5. Jewkes R, Morrell R. Hegemonic masculinity, violence, and gender equality: using latent class analysis to investigate the origins and correlates of differences between men. Men Mascul. 2018;21(4):547-71. [Google Scholar]

6. Yu C, Zuo X, Blum RW, Tolman DL, Kågesten A, Mmari K, Meyer SD, Michielsen K, Basu S, Acharya R, Lian Q, Lou C. Marching to a different drummer: a cross-cultural comparison of young adolescents who challenge gender norms. J Adolesc Health. 2017;61(4):S48-S54. [PubMed] [Google Scholar]

7. Peitzmeier SM, Kågesten A, Acharya R, Cheng Y, DelanyMoretlwe S, Olumide A, Blum RW, Sonenstein F, Drecker MR. Intimate partner violence perpetration among adolescent males in disadvantaged neighborhoods globally. J Adolesc Health. 2016;59(6):696-702. [PubMed] [Google Scholar]

8. Connell RW, Messerschmidt JW. Hegemonic masculinity: rethinking the concept. Gender Soc. 2005;19(6):82959. [Google Scholar]

9. Klugman J, Hanmer L, Twigg S, Hasan T, McCleary-Sills J, Santamaria J. Voice and agency: empowering women and girls for shared prosperity. Washington, DC: World Bank; 2014. [Google Scholar]

10. Zimmerman LA, Li M, Moreau, C, Wilopo S, Blum R. Measuring agency as a dimension of empowerment among young adolescents globally; findings from the Global Early Adolescent Study. SSM Popul Health. 2019;8. [PubMed] [Google Scholar]

11. Gammage S, Kabeer N, Rodgers YM. Voice and agency: where are we now? Femin Econ. 2016;22(1):1-29. [Google Scholar]

12. Landry M, Vyas AN, Malhotra G, Nagaraj N. Adolescents' development of gender equity attitudes in India. Int J Adolesc Youth. 2020;19(1):99-103. [Google Scholar]

13. Hill JP, Lynch ME. The intensification of gender-related role expectations during early adolescence. In: BrooksGunn J, Peterson AC, editors. Girls at puberty. NY: Springer US; 1983. p. 201-8. [Google Scholar]

14. Vyas AN, Malhotra G, Nagaraj NC, Landry M. Gender attitudes in adolescence: evaluating the girl rising gender-sensitization program in India. Int J Adolesc Youth. 2020;25(1):126-39. [Google Scholar]

15. Kågesten A, Gibbs S, Blum RW, Moreau C, ChandraMouli V, Herbert A, Amin A. Understanding factors that shape gender attitudes in early adolescence globally: a mixed-methods systematic review. PloS One. 2016;11(6):e0157805. [PubMed] [Google Scholar]

16. Tolman DL, Davis BR, Bowman CP. "That's just how it is": a gendered analysis of masculinity and femininity ideologies in adolescent girls' and boys' heterosexual relationships. J Adolesc Res. 2016;31:3-31. [Google Scholar]

17. Thekkudan J, Menon R, Thomas M. Understanding social norms underpinning domestic violence in India. 
Technical background paper for Oxfam India's Campaign on elimination of violence against women and girls. Oxfam; 2016.

18. Gurang YB, Suwal BR, Pradhan MS, Tamang MS. Getting REDD right for women: an analysis of the barriers and opportunities for women's participation in the REDD+ sector in Asia. USAID [United States Agency for International Development]. USAID; Sep 2011.

19. International Institute for Population Sciences (IIPS) and ICF. National Family Health Survey (NFHS-4), 201516: India. Vol I. International Institute of Population Science, ICF; 2017. p. 1-192.

20. Patkar A. Socio-economic status and female literacy in India. Int J Edu Dev. 1995;15(4):401-9. [Google Scholar]

21. Acharya M, Bennett $L$. The status of women in Nepal: a critical review. Kathmandu: Center for Economic Development and Administration; 1981.

22. Pennels L. Girl's and women's education policies and implementation mechanism, case study: Nepal. Bangkok: UNESCO principal regional office for Asia and the Pacific; 1998.

23. Panthhe KP. Gender difference in rural urban education in Nepal. Eur J Edu Sci. 2015;2(2):61-79. [Google Scholar]

24. The World Bank [Internet]. Proportion of seats held by women in national parliaments (\%); 1998 [cited 2021 Sep 2]. Available from: https://data.worldbank.org/ indicator/SG.GEN.PARL.ZS

25. Achyut $P$, Bhatla N, Verma H, Uttamacharya, Singh G, Bhattacharya S, Verma R. Towards gender equality: the GEMS journey thus far. New Delhi: International Center for Research on Women; 2016.

26. Nanda G. Compendium of gender scales. Washington, DC: FHI, 360; 2011.

27. Kline RB. Principles and practice of structural equation modeling. 2nd ed. United Kingdom: Guilford Publications; 2005.

28. Joreskog K, Sorbom D. Structural equation modelling: guidelines for determining model fit. NY: University Press of America; 1993.

29. Rotter JB. Generalized expectancies for internal versus external control of reinforcement. Psychol Monogr. 1996;80(1):1. [PubMed] [Google Scholar]

30. Stanley LM, Edwards MC. Reliability and model fit. Educ Psychol Meas. 2016;76(6):976-85. [PubMed] [Google Scholar] 